\title{
Development of a $16 S r R N A$ PCR-RFLP Assay for Bartonella Identification: Applicability in the Identification of Species Involved in Human Infections
}

\author{
Luis J. del Valle ${ }^{1}$, Michael L. Jaramillo ${ }^{2}$, Miguel Talledo ${ }^{2}$, Maria J. Pons ${ }^{3}$, Lidia Flores ${ }^{2}$, Ruth L. Quispe ${ }^{2}$, \\ Pablo Ramírez ${ }^{2}$, Ruth García-de-la-Guarda ${ }^{2}$, Débora Alvarado ${ }^{2}$, Abraham Espinoza-Culupú ${ }^{2}$, Juana del \\ Valle $^{4,5}$, Martha Vargas ${ }^{6}$, Joaquim Ruíz ${ }^{3, *}$
}

\author{
${ }^{1}$ Centre de Biotecnología Molecular, Departamentd’Enginyeria Química, Universitat Politècnica de Catalunya, Barcelona, Spain \\ ${ }^{2}$ Laboratorio de Microbiología Molecular y Biotecnología, Facultad de Ciencias Biológicas, Universidad Nacional Mayor de San Marcos, \\ Lima, Perú \\ ${ }^{3}$ Barcelona Centre for International Health Research (CRESIB), Hospital Clinic, Universitat de Barcelona, Spain \\ ${ }^{4}$ Universidad Peruana de Ciencias Aplicadas, Lima, Perú \\ ${ }^{5}$ Instituto de Investigación Nutricional, Lima, Perú \\ ${ }^{6}$ Hospital Clinic de Barcelona, Barcelona, Spain \\ *Corresponding Author: joruiz@clinic.ub.es
}

Copyright (C) 2014 Horizon Research Publishing. All rights reserved.

\begin{abstract}
We designed a $16 S$ rRNA gene PCR-RFLP scheme to identify all currently described Bartonella spp. The $16 S$ rRNA genes of all Bartonella spp. were in-silico analyzed in order to design a RFLP technique able to discriminate among different species. The restriction enzymes selected were MaeIII, MseI, Sau96I, BsaAI, DrdI, FokI, BssHII, BstUI, AluI, TspDTI and HphI which, according to a decision-making tree, facilitated the differentiation of all the currently described species of Bartonella.The technique was experimentally tested in different species of Bartonella, including human pathogenic B. bacilliformis and B. henselae with a $100 \%$ of concordance with the in-silico predicted patterns.This novel RFLP assay could be used to identify both human and non-human pathogenic Bartonella in diagnostic, phylogenetic and epidemiologic studies.
\end{abstract}

Keywords Bartonella, PCR-RFLP, I6s rRNA Gene, Identification

\section{Introduction}

Bartonella spp. are vector-transmitted Gram-negative bacteria which are members of the $\alpha$-proteobacteria group phylogenetically close to the Rickettsiie, as well as Brucella spp., Agrobacterium spp., and Afipia spp. [1-3].

The number of species of the Bartonella genus described has been raised greatly in the last years. To date more than 29 species belonging to the genera Bartonella have been described most of them as a cause of infections in humans and animals [1,4-10]. Thus, Bartonella bacilliformis is the causative agent of Carrion's disease, a two-phase human infectious disease (acute or hematic phase, known as Oroya Fever that may be fatal in the absence of treatment, and an eruptive or tissue phase, known as Peruvian Wart) which is endemic in Andean areas of Peru, Ecuador and Colombia [9]. Another relevant illness due to Bartonella species are Cat-Scratch disease by Bartonella henselae or Trench Fever due to Bartonella quintana. Additionally a series of other species such as Bartonella grahamii, Bartonella bovis or Bartonella rochalimae among others have been isolated as a causative of different infections $[4,9,11,12]$.

Currently, standard identification techniques for Bartonella spp. include serology methodologies, culture techniques to recover viable organisms or PCR detection of specific sequences from DNA in blood and tissue samples [4]. However, these techniques are cumbersome, or do not provide univocal identification or are only able to detect some specific Bartonella spp. among other limitations [4]. Additionally, the members of the Bartonella genus have a fairly neutral biochemical profile, except for the production of peptidases, which may vary among species [11]. In absence of molecular studies, this fact may results in incorrect identification problems. The more suitable molecular tools, as DNA sequencing or MALDI-TOFF [13, 14] remains unavailable in a long series of areas from low and middle income countries, especially in those placed far of main cities. In these areas a gap in the knowledge of etiological causes of febrile syndromes is present. This lack of technical resources usually results in clinical symptoms based diagnosis [14], which may drive to misdiagnosis [14]. Thus, the development of techniques which will be able to be 
implemented in regional health centers will be a valuable tool in order to determine the relevance of the role of Bartonella spp. as a cause of illness in rural low and middle income areas.

Amplification of conserved genes (as $16 \mathrm{~S} r R N A$ or $r p o B$ genes) followed by PCR-products digestion and the analysis of the resulting Restriction Fragment Length Polymorphisms (RFLP) has been successfully used to identify different bacterial genus at a species level [16-18]. In this line, the construction of a decision-making tree [19] with a series of consecutive restrictions, leading to a specific RFLP pattern in one of the consecutive steps has the advantage of early discrimination of species of special interest.

Although different authors designed PCR-RFLP assays for a rapid identification of different Bartonella spp. in the 90 's $[7,20]$, these studies did not evolve in parallel with the description of new Bartonella species and are currently unable to discriminate between a series of newly described species. However, the PCR-RFLP is a flexible technique that may be modified incorporating the current and future newly described species, by selecting new restriction enzymes, or by adding a novel species in its own unique branch in one of the described restrictions of the decision-making tree.

In the present work, we designed an alternative $16 \mathrm{~S} r R N A$ gene PCR-RFLP scheme to identify 29 currently described Bartonella spp. easily applicable to Bartonella spp. with clinical interest such as B. bacilliformis, B. quintana or $B$. henselae.

\section{Materials and Methods}

\subsection{Bioinformatic Analysis of the Restriction Sites for $16 S r R N A$ in Bartonella spp.}

Representative DNA sequences of Bartonella spp. $16 \mathrm{~S}$ $r R N A$ genes were selected from GenBank (Table 1). Regions of $1452 \mathrm{bp}$, flanked by the oligonucleotides $8 \mathrm{~F}$ (5'-AGAGTTTGATCCTGGCTCAG-3') and 1510R (5'-GGTTACCTTGTTACGACTT-3') [18] were aligned and visualized using ClustalW (http://www.clustal.org) and Bioedit (http://www.mbio.ncsu.edu/BioEdit/bioedit.html) software respectively. In some sequences, the end regions were lack, in these cases these regions were considered as conserved.

In-silico analysis for the restriction sites in the 16S rRNA gene was carried out using Restenzym software (http://www.enzim.hu/ tusi/restric/index.html) in order to select the appropriate restriction enzymes. The fragments of the aforementioned in-silico RFLP were separated in a virtual electrophoresis using the pDraw32 software (http://www.acaclone.com/). The fragments smaller than 50 bp were not considered in the analysis.

Additionally, closely related microorganisms such as Brucella melitensis, Ricketsia rickectsi, Erlichia muris and Chlamydia trachomatis were included in the in-silico analysis.

\subsection{Bacteria Culture}

B. bacilliformis CIP 57.17, B. henselae CIP 103737, B. bovis CIP 106692, B. clarridgeiae CIP104772, acquired from the Collection of the Institute Pasteur (Paris, France) were cultured in Columbia Agar plates adding $10 \%$ of sheep blood and incubated at $30{ }^{\circ} \mathrm{C}$ with $5 \%$ of $\mathrm{CO}_{2}$ for 15-45 days. Additionally 7 Bartonella spp. clinical isolates, recovered from blood samples of patients with febrile syndrome, were also included in the study.

\subsection{Purification of genomic DNA}

The cells were collected from the plates and washed with buffer phosphate for three times by centrifugation at $13000 \mathrm{~g}$ during 2 min. The DNA was obtained with the Wizard ${ }^{\circledR}$ Genomic Purification Kit (Promega, Madison, Wi) following the manufacturer's instructions.

An aliquot of DNA was analyzed by establishing the A260:A280 and A260:A230 ratios and electrophoresis at $1 \%$ agarose gel to evidence the quality of purified DNA. The genomic DNA was stored at $-20^{\circ} \mathrm{C}$.

\subsection{Amplification of the $16 \mathrm{~S}$ rRNA and Digestion with Restriction Enzymes}

A fragment of $1452 \mathrm{bp}$ of the $16 S \mathrm{r} R N A$ gene, equivalent to that analyzed in-silico, was amplified using previously described primers and conditions [18]. The amplified products were digested with the $i n$-silico selected restriction enzymes following the manufacturer's instructions and RFLP was visualized by electrophoresis in a $2.5 \%$ agarose gel.

\section{Results and Discussion}

\subsection{Design of in-silico decision-making tree}

The 16S rRNA gene possesses a highly conserved DNA sequence and thus has been previously used to identify microorganisms at species level $[15,18,19]$. In the case of Bartonella genus an alignment matrix of the sequences showed 97-99 \% of homology between species (Table 2). Thus, in this study an easy and rapid technique is proposed to identify Bartonella species based on the development of serial restrictions of the $16 S$ rRNA gene to obtain a RFLP pattern associated with a unique species of the genus. Additionally, this technique has the potential to be used in low or middle resources countries, in which other tecniques may be non-disposable or too expensive to be applied.

The present in-silico analyses focused on Bartonella spp., result in the selection of MaeIII, MseI, Sau96I, BsaAI, DrdI, FokI, BssHII, BstUI, AluI, TspDTI and $H p h \mathrm{I}$ restriction enzymes. Using these enzymes in the sequential manner proposed the 29 Bartonella species currently present in GenBank may be unambiguously identified (Fig 1-6). 


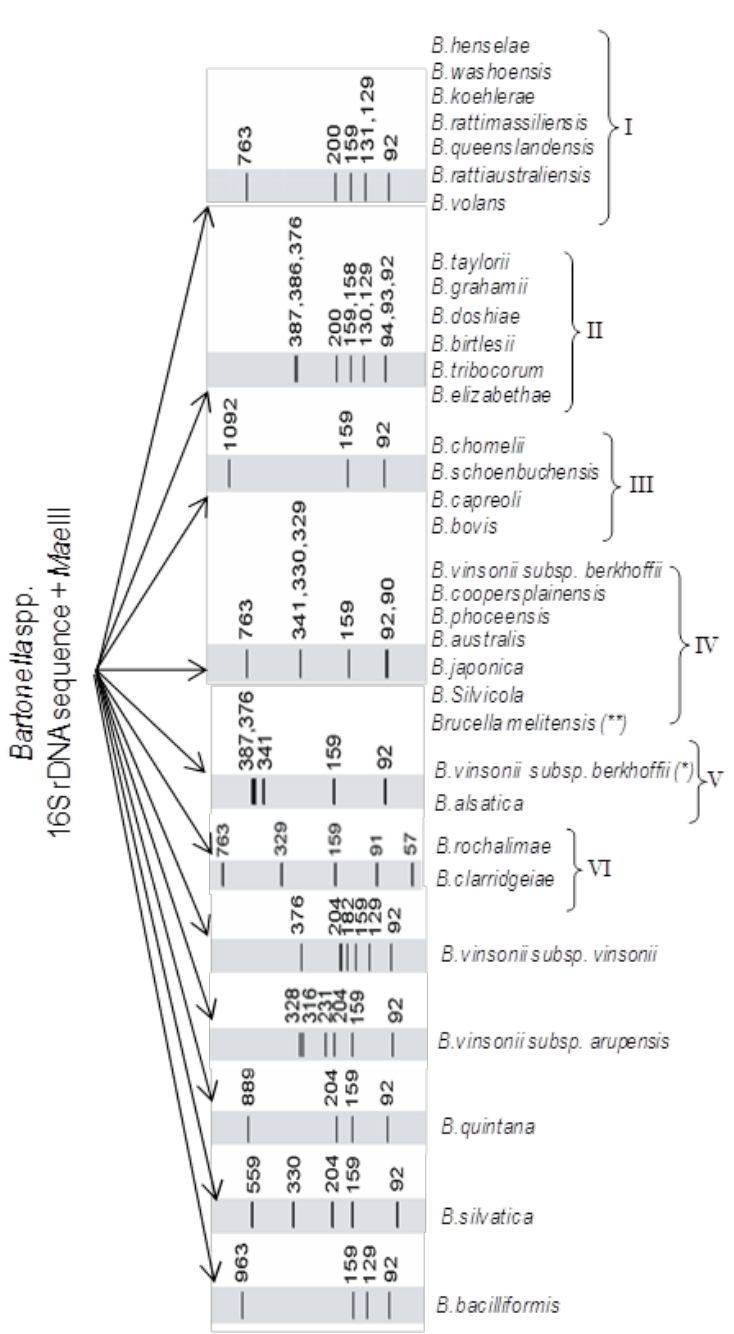

Figure 1. Identification and establishment of clusters of Bartonella species. The patterns were obtained using restriction with MaeIII. *Isolate G7464 (ATCC 35685) of B.vinsonii subsp. berkhoffii. ** Strain ATCC 23457 (CP001489) of Brucella melitensis. In this figure, as in Figures 2 to 7 the proportions have been altered in order to best disposition of the samples sizes.

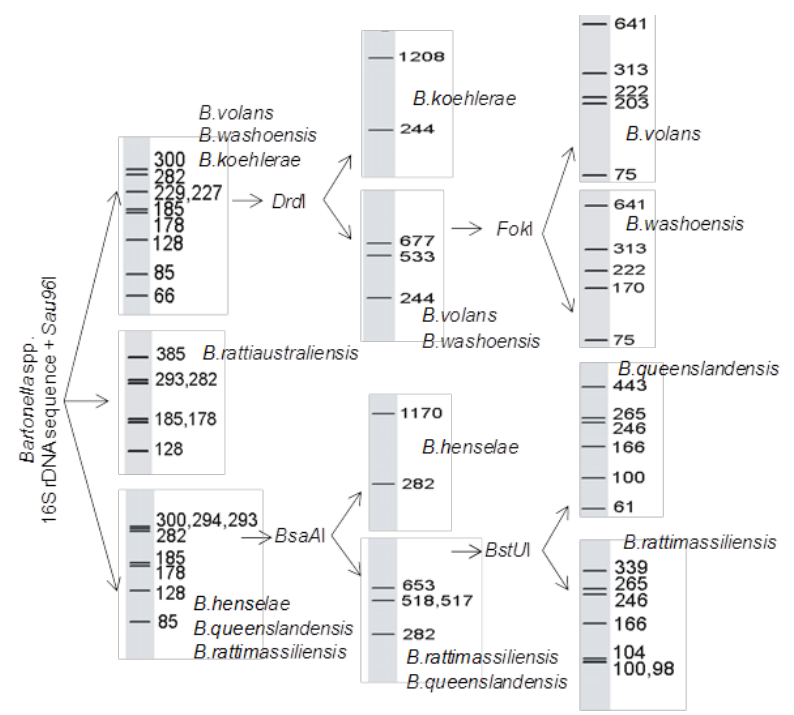

Figure 2. Identification of species included in cluster I. Each enzymatic digestion is always carried out on the $16 \mathrm{~S} r R N A$ amplicon.

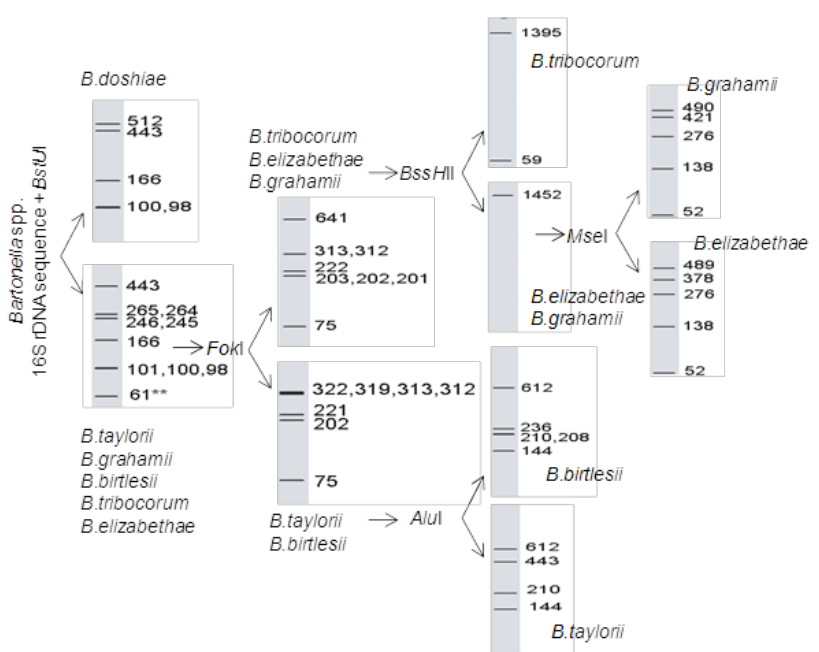

Figure 3. Identification of species included in cluster II. Each enzymatic digestion is always carried out on the $16 \mathrm{~S} r R N A$ amplicon.

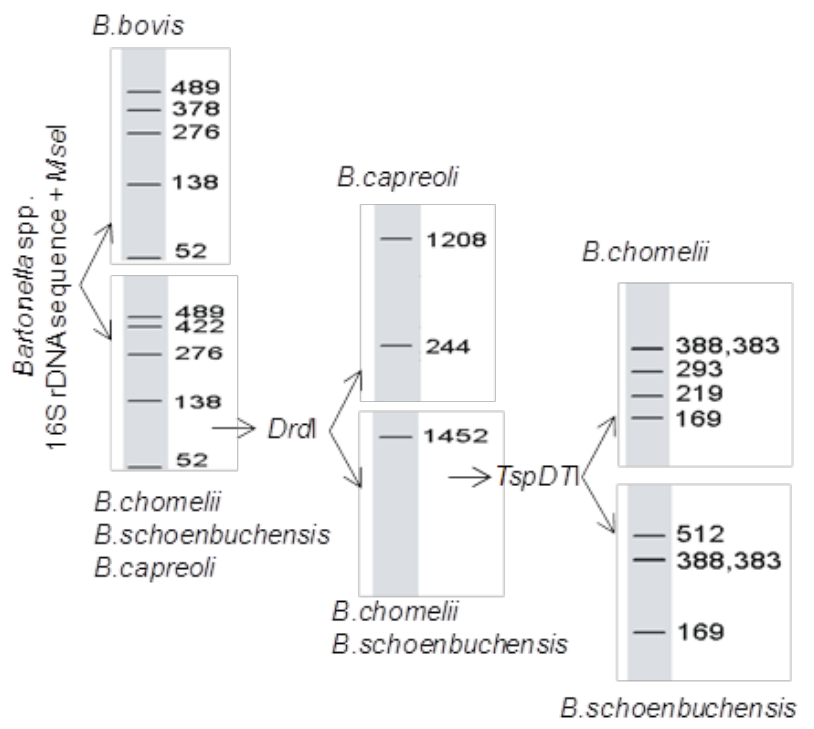

Figure 4. Identification of species included in cluster III. Each enzymatic digestion is always carried out on the $16 \mathrm{~S} r R N A$ amplicon.

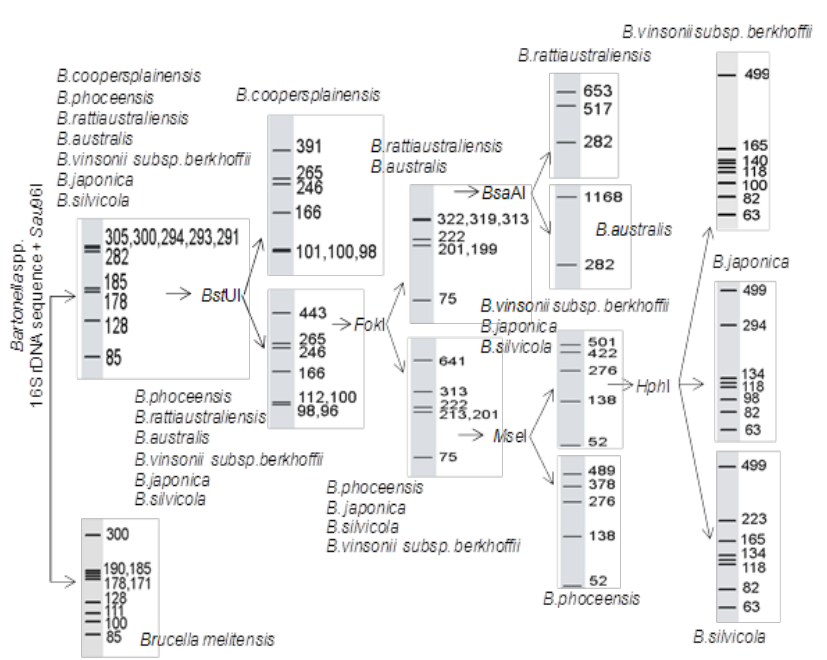

Figure 5. Identification of species included in cluster IV. Each enzymatic digestion is always carried out on the $16 \mathrm{~S} r R N A$ amplicon. 
Table 1. Species of Bartonella used in the restriction bioinformatic analysis.

\begin{tabular}{|c|c|c|c|}
\hline \multirow{2}{*}{ Species } & \multirow{2}{*}{ Strain } & \multicolumn{2}{|c|}{$16 S r R N A$ gene } \\
\hline & & Collection No. & GenBank No. \\
\hline B. alsatica & $\operatorname{IBS} 382^{\mathrm{T}}$ & CIP 1054773 & AJ002139 \\
\hline B. australis & AUST/NH1 ${ }^{\mathrm{T}}$ & CIP $108978^{\mathrm{T}}$ & DQ538394 \\
\hline B. bacilliformis & $\mathrm{KC} 583^{\mathrm{T}}$ & ATCC 35685 & NC_008783 \\
\hline B. birtlesii & IBS $325^{\mathrm{T}}$ & CIP $106294^{\mathrm{T}}$ & AF204274 \\
\hline B. bovis & $91-4 \mathrm{~T}$ & CIP $106692^{\mathrm{T}}$ & AF293391 \\
\hline B. capreoli & IBS $193^{\mathrm{T}}$ & CIP $106691^{\mathrm{T}}$ & AF293389 \\
\hline B. chomelii & $\mathrm{A} 828^{\mathrm{T}}$ & CIP $107869^{\mathrm{T}}$ & AY254309 \\
\hline B. clarridgeiae & 94-F40 & & U64691 \\
\hline B. coopersplainensis & AUST/NH20 & CIP 109064 & EU111759 \\
\hline B. doshiae & $\mathrm{R} 18^{\mathrm{T}}$ & NCTC 12862 & Z31351 \\
\hline B. elizabethae & $\mathrm{F} 9251^{\mathrm{T}}$ & ATCC 49927 & L01260 \\
\hline B. grahamii & $\mathrm{V} 2$ & NCTC 12860 & Z31349 \\
\hline B. henselae & Houston- $1^{\mathrm{T}}$ & ATCC 49882 & NC_005956 \\
\hline B. japonica & Fuji $18-1^{\mathrm{T}}$ & $\mathrm{JCM} 15567^{\mathrm{T}}=\mathrm{CIP} 109861^{\mathrm{T}}$ & AB440632 \\
\hline B. koehlerae & $\mathrm{C}-29^{\mathrm{T}}$ & ATCC 700693 & AF076237 \\
\hline B. phoceensis & 16120 & CIP $107707^{\mathrm{T}}$ & AY515119 \\
\hline B. queenslandensis & AUST/NH12 & CIP 109057 & EU111754 \\
\hline B. quintana & Toulouse & & NC_005955 \\
\hline B. rattiaustraliensis & AUST/NH4 & CIP 109051 & EU111749 \\
\hline B. rattimassiliensis & 15908 & CIP $107705^{\mathrm{T}}$ & AY515120 \\
\hline B. rochalimae & & ATCC BAA-1498 & Contig12 (12399-13873) \\
\hline B. schoenbuchensis & $\mathrm{R} 1^{\mathrm{T}}$ & NCTC $13165^{\mathrm{T}}$ & AJ278187 \\
\hline B. silvatica & Fuji $23-1^{\mathrm{T}}$ & $\mathrm{JCM} 15566^{\mathrm{T}}=\mathrm{CIP} 109862^{\mathrm{T}}$ & AB440636 \\
\hline B. silvicola & Cul-9 & & EF616480 \\
\hline B. taylorii & $\mathrm{M}^{\mathrm{T}}$ & NCTC 12861 & $\mathrm{Z} 31350$ \\
\hline B. tribocorum & IBS $506^{\mathrm{T}}$ & CIP 104576 & AJ003070 \\
\hline B. vinsonii subsp. arupensis & OK $94-513^{\mathrm{T}}$ & ATCC 700727 & AF214558 \\
\hline $\begin{array}{l}\text { B. vinsonii subsp. berkhoffii } \\
\text { B. vinsonii subsp. berkhoffii (*) }\end{array}$ & $\begin{array}{c}93 \mathrm{CO}^{\mathrm{T}} \\
\text { strain } \mathrm{G} 7464\end{array}$ & $\begin{array}{l}\text { ATCC } 51672 \\
\text { ATCC } 35685\end{array}$ & $\begin{array}{l}\text { L35052 } \\
\text { U26258 }\end{array}$ \\
\hline B. vinsonii subsp. vinsonii & Baker $^{\mathrm{T}}$ & ATCC VR-152 & Z31352 \\
\hline B. volans & FSq-1 & ATCC BAA-1451 & EU294521 \\
\hline B. washoensis & NVH1 & & AF070463 \\
\hline
\end{tabular}

A total of 29 species of Bartonella were analyzed in this study, for the case of B.vinsonii were analyzed three subspecies. Negative controls were used in the A total of 29 species of Bartonella were analyzed in this study, for the case of B.vinsonil were analyzed three subspecies. Negative controls were used in
in-silico analysis of RFLP patterns: Chlamydia trachomatis strain HAR-13 (D89067), Brucella melitensis ATCC 23457 (CP001489), Ehrlichia muris AS145 (U15527), Rickettsii rickectsi strain R (L36217). (*) Isolate G7464 of B. vinsonii subsp. berkhoffii used in other publications (11) close related to type strain 93 CO1T of B.vinsonii subsp. berkhoffii. 
Table 2. $16 S r R N A$ similarity values obtained from a multiple-sequence alignment.

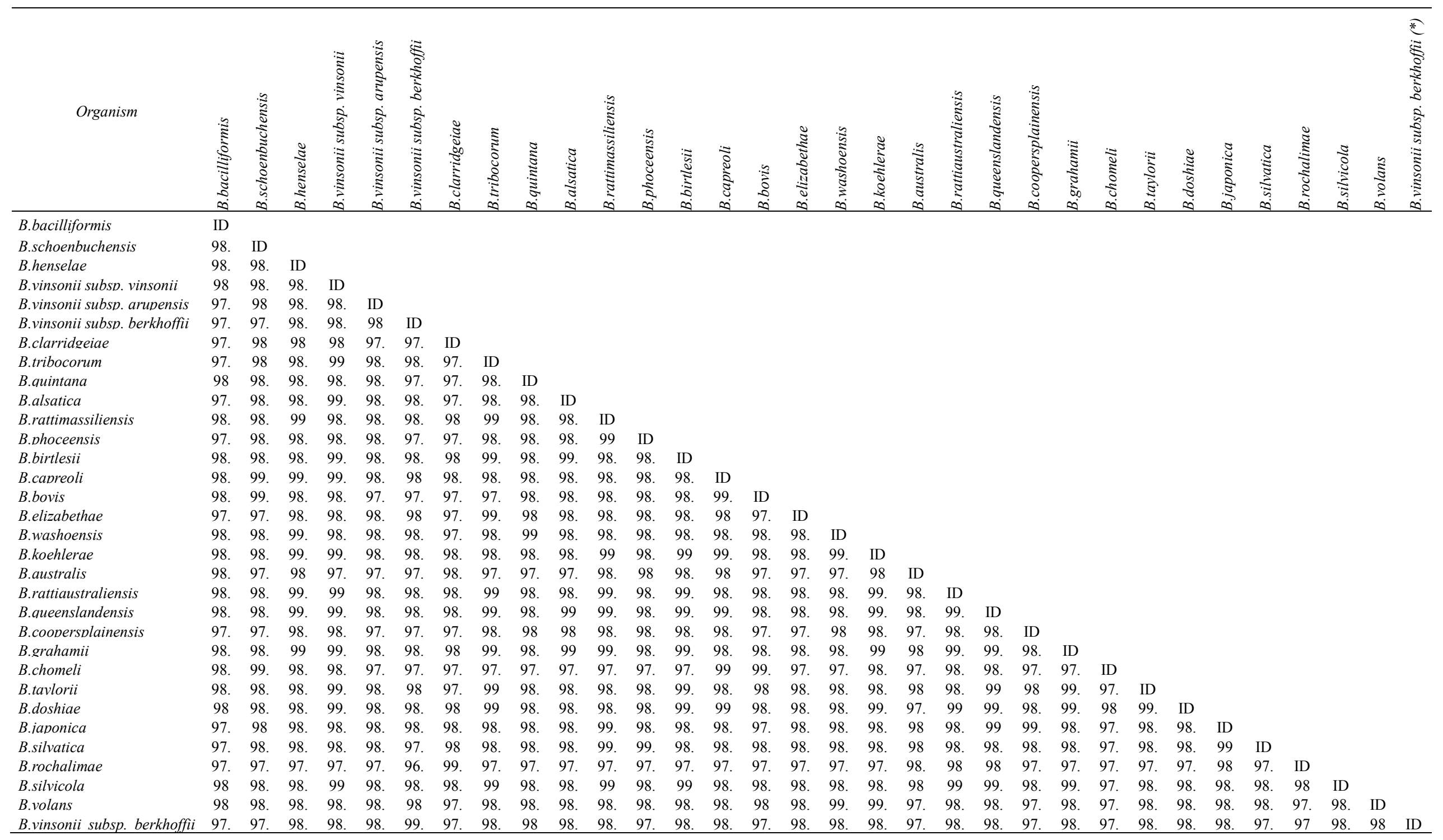

* Isolate G7464 (ATCC 35685) of B.vinsonii subsp. berkhoffii 

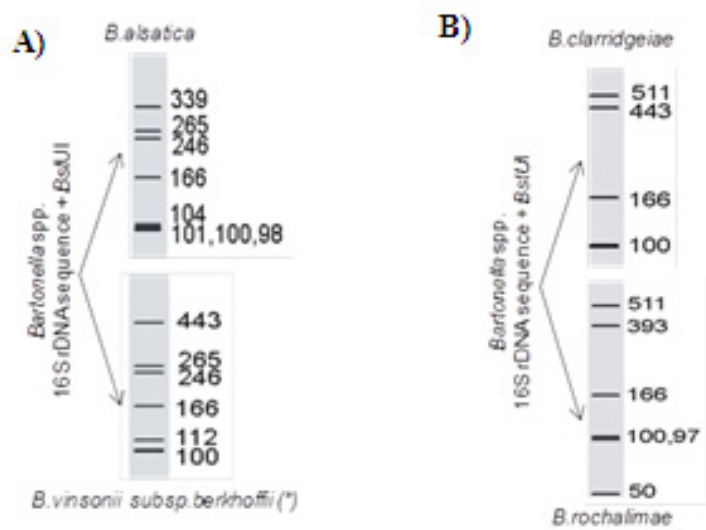

Figure 6. A) Identification of species included in cluster V. (*) Isolate G7464 (ATCC 35685) of B.vinsonii subsp. berkhoffii. B) Identification of species included in cluster VI. Each enzymatic digestion is always carried out on the $16 S$ rRNA amplicon.

The RFLP decision-making tree is started using MaeIII. This should allow among B.bacilliformis, B.quintana, B.silvatica, B.vinsonii subsp. vinsonii, and B.vinsonii subsp. arupensis to be unambiguously and accurately differentiated from the remaining Bartonella (Fig. 1) in a single step.

The interest of this point is specially related to the clinical interest of $B$. bacilliformis and $B$. quintana as human pathogens. Thus, $B$. bacilliformis and $B$. quintana are the etiologic agents for Carrion's disease (acute Oroya fever and angiomatosis, endocarditis, chronic bacteremia, pericarditis), respectively [4]. Referring to non-Bartonella included in the analysis, only Brucella melitensis results in a common pattern with some Bartonella species (cluster IV) in the MaeIII restriction, but was quickly separates in the cluster analysis (Fig 5).

\subsection{Applicability of the PCR-RFLP identification}

This rapid technique may be of special interest to describe more in depth the real role of different Bartonella spp. in human infections being of specially interest in limted-resources countries. Until early 1990, only one Bartonella species (B. bacilliformis) was implicated in human pathology, but currently around ten species have been related to different human pathologies [4]. Moreover, identifications based on clinical findings may not be correct as in a suspicious case of Oroya's Fever, pathology related to $B$. bacilliformis, which was described as produced by $B$. rochalimae [12].

The use of molecular tools may overcome these erroneous bacterial identifications obtained on the basis of clinical presentations or classical techniques [12, 18, 21] This problem is especially relevant in fastidious microorganisms such as the members of the Bartonella genus.

Despite it has been described that some members of the Bartonella genus are able to grown from blood stored at $4^{\circ} \mathrm{C}$, even being maintained for more than 2 years [22], the growth and isolation of Bartonella species on blood agar plates generally requires a prolonged incubation period (an average of 21 days) and is rarely successful. This fact may be considered as a pitfall, because the need of dispose of cultured bacteria. However, the RFLP method provides a broad application, even in culture-negative infected material [23]. Moreover, the amplification of the $16 S r R N A$ gene has been successfully used as rapid Bartonella spp. diagnosis tool [14]. Thus, RFLP analysis of the $16 S$ rRNA gene in Bartonella can be a useful molecular tool for the identification of Bartonella species.

An interesting possibility may be the presence of two different $16 S r R N A$ sequences in the same microorganism. This fact has been showed in the case of $B$. henselae, in which 2 different $16 S r R N A$ sequences have been found, and isolates presenting both together have been described [24, 25]. This $16 S r R N A$ gene variants has been namely as type 1 , with has $B$. henselae Houston-1 as representative strain, and type 2, with has $B$. henselae Urlly8 as a representative strain (GenBank access: AF214556).

The small differences among these two variants ( 2 bases plus 1 gap) do not affect the proposed decision-making tree. Moreover, despite the strongly identity between these two variants, the use of the restriction enzymes DdeI or Bsu36I may allow arriving to determine the exact variant(s) presents in the sample, because the presence of a specific digestion point in the $16 S r R N A$ gene belonging to the type 1 which is absent in those belonging to type 2 .

\subsection{Experimental application of the PCR-RFLP to identify several Bartonella spp}

Experimentally, we have run the RFLP analysis of the $16 \mathrm{~S}$ rRNA gene in B.bacilliformis, B.henselae, B.bovis and B.clarridgeiae (Fig. 7). In all cases, the electrophoresis pattern of the fragments obtained in the digestion with MaeIII was different in each species and occurred in accordance to the predicted pattern obtained using bioinformatics tools.

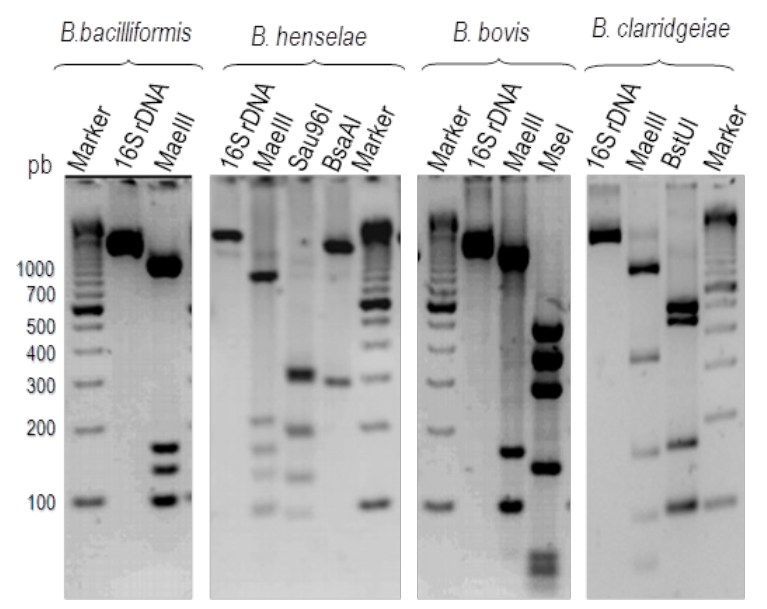

Figure 7. Restriction profiles obtained after endonuclease digestion (MaeIII, MseI, Sau96I, BsaAI, or BstUI) of the amplified 16S rRNA gene with the universal primer set $8 \mathrm{~F}$ and $1510 \mathrm{R}$. Products were electrophoresed in $2.5 \%(\mathrm{w} / \mathrm{v})$ agarose and visualized with Sybr Safe (Invitrogen, Eugene, OR). Molecular size marker was a 100bp (Invitrogen). 
Additionally, the RFLP-technique was also tested in a series of Bartonella spp. clinical isolates proceeding from blood cultures. In all cases the PCR-RFLP results in an unambiguous identification. Thus, 6 cases were identified as $B$. bacilliformis, while the remaining as $B$. elizabethae (data not show). In the seven cases the sequencing of the $16 \mathrm{~S} r R N A$ gene confirms this identification.

The RFLP technique has previously been used for rapid identification of $B$. henselae in the Cat-Scratch disease [7]. Endonuclease digestion of the $16 S$ rRNA gene with DdeI resulted in fragments of approximately 410 and 210 bp for B.henselae, B.quintana, B.elizabethae, B.vinsonii, and B.clarridgeiae. A third fragment of approximately $380 \mathrm{bp}$ was observed in all these strains except B.clarridgeiae. Although other species-specific products ranged from 100 to $280 \mathrm{bp}$, B.elizabethae and B.vinsonii berkhoffii were barely identical [7], besides further studies showed a similar pattern in B. bacilliformis [9]. Additionally, in last years a high number of Bartonella species has been described, and, to our knowledge, no study to adapt this proposal has been made.

\section{Conclusion}

The description of new human pathogenic species of the Bartonella genus makes improvement of the molecular techniques in the detection and identification of these species necessary. The 16S rRNA gene is used to establish the phylogenetic taxonomy of the Bartonella genus due to the high interspecies similarity. This same approach has been used to develop a molecular assay by RFLP analysis able to both differentiate among all the currently described Bartonella species and to be modified according to future knowledge. This simple, rapid method provides a broad application and can be expected to significant increase our understanding of the epidemiology of this group of important human pathogens.

\section{Acknowledgements}

This work has been partially supported by Optimus Foundation, CONCYTEC (Consejo Nacional de Ciencia, Tecnología e Innovación Tecnológica, Perú) grant 323-2010-CONCYTEC-OAJ, UNMSM-VRI (Universidad Nacional Mayor de San Marcos - Vicerrectorado de Investigación, Perú) grant 111001141, and by grant PI11/00983 from the Instituto de Salud Carlos III-ISCIII (Spain).

L.J.dV has been supported by the AECID (Agencia Española de Cooperación Internacional al Desarrollo) grant PCI-A/9727/07, and DURSI, Generalitat de Catalunya, grant 2009SGR-1208.

JR has a fellowship from the program I3, of the ISCIII (grant number: CES11/012).

\section{REFERENCES}

[1] R.J.Birtles, T.G.Harrison, N.A.Saunders, D.H.Molyneux, Proposals to unify the genera Grahamella and Bartonella, with descriptions of Bartonella talpae comb. nov., Bartonella peromysci comb. nov., and three new species, Bartonella grahamii sp. nov., Bartonella taylorii sp. nov., and Bartonella doshiae sp. nov. International Journal of Systematic Bacteriology. Vol: 45, No: 1, 1-8. 1995.

[2] D.J.Brenner, S.P.O'Connor, H.H.Winkler, A.G.Steigerwalt. Proposals to unify the genera Bartonella and Rochalimaea, with descriptions of Bartonella quintana comb. nov., Bartonella vinsonii comb. nov., Bartonella henselae comb. nov., and Bartonella elizabethae comb. nov., and to remove the family Bartonellaceae from the order Rickettsiiles. International Journal of Systematic Bacteriology. Vol: 43, No:4, 777-786, 1993.

[3] W.G.Weisburg, C.R.Woese, M.E.Dobson, E.Weiss, A common origin of Rickettsiie and certain plant pathogens. Science. Vol: 230 No:4725. 556-558. 1985.

[4] J.R.Blanco, I.Jado, M.Marín, I.Sanfeliu, A.Portillo, P.Anda, I.Pons, J.A.Oteo. Diagnóstico microbiológico de las infecciones por patógenos bacterianos emergentes: Anaplasma, Bartonella, Rickettsii, Tropheryma whipplei. Enfermedades. Infecciosas y Microbiologia Clinica. Vol:26, No: 9, 573-580. 2008.

[5] L. Guptill. Bartonellosis. Veterinary Microbiology. Vol: 140, No: 3-4, 347-359. 2010.

[6] E.Huarcaya, C.Maguiña, R.Torres, J.Rupay, L.Fuentes. Bartonelosis (Carrion's disease) in the pediatric population of Peru: an overview and update. Brazilian Journal of Infectious Diseases Vol:8, No:5, 331-339. 2004.

[7] D.L.Kordick, E.JHilyard, T.L.Hadfield, K.H.Wilson, A.G.Steigerwalt, D.J.Brenner, E.B.Breitschwerdt. Bartonella clarridgeiae, a newly recognized zoonotic pathogen causing inoculation papules, fever, and lymphadenopathy (cat scratch disease). Journal of Clinical Microbiology. Vol:35, No:7, 1813-1818. 1997.

[8] D.L.Kordick, B.Swaminathan, C.E.Greene, K.H.Wilson, A.M.Whitney, S.O'Connor, D.G.Hollis, G.M.Matar, A.G,Steigerwalt, G.B.Malcolm., P.S.Hayes, T.L.Hadfield, E.B.Breitschwerdt, D.J.Brenner. Bartonella vinsonii subsp. berkhoffii subsp. nov., isolated from dogs; Bartonella vinsonii subsp. vinsonii; and emended description of Bartonella vinsonii. International Journal of Systematic Bacteriology. Vol:46, No:3, 704-709. 1996.

[9] C.Maguiña, H.Guerra, P.Ventosilla, Bartonellosis. Clinical Dermatology. Vol:27, No:3, 271-280. 2009.

[10] W.Saisongkorh, J.M.Rolain, Y.Suputtamongkol, D.Raoult. Emerging Bartonella in Humans and Animals in Asia and Australia. Journal of the Medical Association of Thailand. Vol:92, No:5, 707-731. 2009.

[11] E.B.Breitschwerdt, D.L.Kordick, Bartonella infection in animals: carriership, reservoir potential, pathogenicity, and zoonotic potential for human infection. Clinical Microbiology Reviews. Vol:13 No:3 428-438. 2000.

[12] M.E.Eremeeva, H.L.Gerns, S.L.Lydy, J.S.Goo, E.T.Ryan, S.SMathew, M.J.Ferraro, J.M.Holden, W.L.Nicholson, G.A.Dasch, J.E.Koehler. Bacteremia, fever, and 
splenomegaly caused by a newly recognized bartonella species. New England Journal of Medicine. Vol:356, No:23 2381-2387. 2007

[13] P.E.Fournier, C.Couderc, S.Buffet, C.Flaudrops, D.Raoult. Rapid and cost-effective identification of Bartonella species using mass spectrometry. Journal of Medical Microbiology, Vol:58, No:9, 1154-1159. 2009.

[14] J.Ruiz, W.Silva, C.Tinco, M.J.Pons, L.del Valle, C.Gomez, J.Bazan, M.Vargas, D.Champin, J.del Valle Mendoza. Etiological and molecular diagnostic of Carrion's disease in patients from Cajamarca - Perú. International Journal of Infectious Diseases. Vol:16 No: Suppl1, e252-e254. 2012.

[15] N.Borrell, S.G..Acinas, M.J.Figueras, A.J.Martínez-Murcia. Identification of Aeromonas clinical isolates by restriction fragment length polymorphism of PCR-amplified 16S rRNA genes. Journal of Clinical Microbiology Vol:35, No:7 1671-1674. 1997.

[16] M.Ferreira-Tonin, J.Rodrigues-Neto, R.Harakava, S.A.Destéfano. Phylogenetic analysis of Xanthomonas based on partial rpoB gene sequences and species differentiation by PCR-RFLP. International Journal of Systematic and Evolutionary Microbiology. Vol:62, No:Pt 6, 419-424. 2012.

[17] J.B.Messick, L.M.Berent, S.K.Cooper. Development and evaluation of a PCR-based assay for detection of Haemobartonella felis in cats and differentiation of $\mathrm{H}$. felis from related bacteria by restriction fragment length polymorphism analysis. Journal of Clinical Microbiology Vol:36, No2, 462-466. 1998.

[18] E.Z.Salazar de Vegas, B.Nieves, M.Araque, E.Velasco, J.Ruiz, J.Vila. Outbreak of infection with Acinetobacter strain RUH 1139 in an intensive care unit. Infection Control and
Hospital Epidemiology. Vol:27. No:4 397-403. 2006.

[19] M.J.Figueras, L.Soler, M.R.Chacón, J.Guarro, A.JMartínez-Murcia. Extended method for discrimination of Aeromonas spp. by $16 \mathrm{~S}$ rDNA RFLP analysis. International Journal of Systematic and Evolutionary Microbiology. Vol:50 No:Pt 6, 2069-2073. 2000.

[20] R.J. Birtles. Differentiation of Bartonella species using restriction endonuclease analysis of PCR-amplified 16S rRNA genes. FEMS Microbiology Letters. Vol: 129, No: 2-3, 261-266. 1995.

[21] O.Ormen, P.E.Granun, J.Lassen, M.J.Figueras. Lack of agreement between biochemical and genetic identification of Aeromonas spp. APMIS. Vol:113, No:3 203-207. 2005.

[22] J.Ruiz, W.Silva, M.J.Pons, L.J.del Valle, C.R.Tinco, V.D.Casabona, C.Gomes, J.Bazan, V.Zavaleta, H.Cornejo, D.Champin, J.del Valle. Long time survival of Bartonella bacilliformis in blood stored at $4{ }^{\circ} \mathrm{C}$. A risk for blood transfusions. Blood Transfusion. Vol:10, No:4, 563-564. 2012.

[23] D.Rodrick, B.Dillon, M.Dexter, I.Nicholson, S.Marcel, D.Dickeson, J.Iredell. Culture-Negative Endocarditis Due to Houston Complex Bartonella henselae Acquired in Noumea, New Caledonia. Journal of Clinical Microbiology. Vol: 42, No:4, 1846-1848. 2004

[24] J Viezens J, M.Arvand. Simultaneous presence of two different copies of the 16S rRNA gene in Bartonella henselae. Microbiology. Vol 154, No:9, 2881-2886. 2008

[25] V.V.Ebani, F.Bertelloni, F.Fratini. Occurrence of Bartonella henselae types I and II in Central Italian domestic cats. Research in Veterinary Science. Vol:93 No:4, 63-66. 2012 